University of Nebraska - Lincoln

DigitalCommons@University of Nebraska - Lincoln

Faculty Publications, Department of Psychology

Psychology, Department of

September 2004

\title{
Individual and social influences on ethnic identity among Latino young adults
}

Lenna L. Ontai-Grzebik

University of California, Davis

Marcela Raffaelli

University of Nebraska-Lincoln, mraffaelli1@unl.edu

Follow this and additional works at: https://digitalcommons.unl.edu/psychfacpub

Part of the Psychiatry and Psychology Commons

Ontai-Grzebik, Lenna L. and Raffaelli, Marcela, " Individual and social influences on ethnic identity among Latino young adults" (2004). Faculty Publications, Department of Psychology. 32.

https://digitalcommons.unl.edu/psychfacpub/32

This Article is brought to you for free and open access by the Psychology, Department of at DigitalCommons@University of Nebraska - Lincoln. It has been accepted for inclusion in Faculty Publications, Department of Psychology by an authorized administrator of DigitalCommons@University of Nebraska - Lincoln. 


\section{Individual and Social Influences on Ethnic Identity Among \\ Latino Young Adults}

Lenna L. Ontai-Grzebik

University of California, Davis

Marcela Raffaelli

University of Nebraska, Lincoln

Building on prior Latino ethnic identity research, this study had three goals: describe age-related trends in ethnic identity among young adults, examine relations among ethnic identity and individual factors, and explore the impact of family and peer socialization on ethnic identity. The participants (two hundred 19-to 30-year-olds; mean age $=22.5$ ) completed self-report surveys sent to Latino undergraduate and graduate students enrolled in four midwestern institutions of higher education. The findings suggest individual factors are strong predictors of ethnic identity during early adulthood; respondents who were younger, high on Latino orientation, spent more time in the United States, and whose parents had more formal education reported high levels of ethnic identity achievement. In contrast, ethnic identity exploration was higher among individuals whose parents preferred they date Latinos and had less formal education. The findings contribute knowledge regarding ethnic identity and suggest directions for future research on its development among diverse populations.

Keywords: ethnic identity; socialization; Latino; family; peer group

Traditional identity issues such as love, work, and ideology described by Erickson (1968) are theorized to be central concerns in the development of adolescents and young adults in Western societies (e.g., Arnett, 2001; Erickson, 1968; Marcia, 1980). Research with primarily White, middle-class samples has confirmed the value of Erikson's model (Marcia, 1966, 1980; Waterman, Geary, \& Waterman, 1974; Waterman \& Goldman, 1976); how

This research was funded by grants to Marcela Raffaelli from the National Institute of Mental Health (RO3 $\neg$ MH57650) and by the University of Nebraska Research Council. Research assistance was provided by Jennifer Crispo, Jennifer Haase, Stephanie Hewitt, Sarah Kepple, Lynn Marcus, Nicole Miller, Tammy Pfeifer, Katie Pickett, Julie Siepker, Kathryn Wilke, and Byron Zamboanga. Address correspondence to Marcela Raffaelli, Department of Psychology and Institute for Ethnic Studies, 238 Burnett Hall, University of Nebraska, Lincoln, NE 68588-0308; e-mail: mraffaelli1@unl.edu. 
ever, scholars have recognized that the process of identity development is markedly different among ethnically diverse adolescents and young adults in the United States. For such individuals, identity development presents a unique challenge because, in addition to negotiating the traditional domains of identity, they must also decide what their ethnicity means to them (Phinney, 1990); that is, they must develop a sense of ethnic identity.

Ethnic identity is conceptualized as that part of a person's self-knowledge defined by membership in, and emotional connection to, an ethnic group (Phinney, 1992; Tajfel, 1981). The importance of developing a defined sense of ethnic identity is supported by a body of literature linking ethnic identity development and self-esteem, self-concept, use of proactive styles to disprove stereotypes, and positive social interactions with others, although results vary across studies (see Phinney, 1990, and Phinney \& Kohatsu, 1997, for reviews). A number of questions relating to the development of ethnic identity remain. These include when ethnic identity formation is completed, factors linked to individual differences in strength of ethnic identity, and the identification of factors influencing ethnic identity formation. The goal of the current analysis was to begin addressing these questions in a sample of Latino young adults.

Latinos (individuals of Hispanic or Latin American origin or descent living in the United States) offer a unique opportunity to examine ethnic identity formation given differences from other ethnic minority populations on factors that have implications for cultural retention and transmission. One such factor is that most Latino subgroups in the United States are not isolated from their countries of origin as has been true of most other groups, including involuntary immigrants like African Americans and voluntary immigrants from Europe. For example, many Mexican Americans now living in the southwestern part of the United States are descended from Mexicans who became U.S. citizens when Mexico ceded the land to the United States under the terms of the Treaty of Guadalupe Hidalgo in 1848. As well, the countries of origin of most Latino populations in the United States are geographically closer than those of other immigrant groups, permitting regular travel back to countries of origin when political conditions permit. Another unique feature is that Latino immigration has occurred primarily in the last 3 decades, allowing migrants to take advantage of technological advances to maintain contact (e.g., air travel, long-distance telephone calling, faxes, and e-mail). Finally, because Latino populations have endured generations of exclusion and discrimination, full integration into mainstream society has been barred to them, making issues of ethnicity and identity highly salient. Such circumstances create a unique cultural environment for Latino adolescents; consequently, the process of attaining a sense of ethnic identity can be highly challenging as the disparity between the family's values and those of the majority culture are made more prominent by the maintenance of strong ties to the family's culture of origin.

Across ethnic groups, the process of ethnic identity development is thought to parallel the process of ego identity development. In Marcia's (1966) ego identity status model, individuals are classified based on the extent to which they have explored identity options and made commitments to particular aspects of identity (e.g., occupation, political beliefs). Individuals classified as diffuse have not actively explored or made commitments to an identity, whereas those who are foreclosed have made commitments without exploration. Individuals who are in the process of active exploration but have not yet made commitments are in moratorium, whereas those who have explored their options and committed to an identity have an achieved identity. Underlying this developmental process are cognitive advancements and experiences that allow individuals to explore possible identity options.

Theorists have described a similar developmental process occurring for ethnic identity. Precursors to the development of a fully fledged sense of ethnic identity emerge during childhood (Bernal, Knight, Garza, Ocampo, \& Cota, 1990), but it is not until youth develop the capacity for abstract reasoning that they can understand the meaning and permanency of their group membership (Bernal \& Knight, 1997; Knight, Bernal, Garza, \& Cota, 1993). Once adolescents have developed the capacity to reflect critically on their ethnicity and how their behaviors and feelings relate to it, they experience a series of stages in their search for ethnic identity. These stages were explicated by Phinney (1989) within a model of ethnic identity development based on Marcia's ego identity status model. Phinney (1992) suggests that prior to adolescence, ethnic minority individuals have taken on the values and attitudes to which they have been exposed with little questioning or thought. Thus, they may engage in ethnic rituals and practices without understanding their significance (equivalent to foreclosed). Attainment of advanced cognitive abilities enables adolescents to enter a second stage marked by questioning of the meaning of cultural customs and their ethnic heritage and active exploration of their ethnic identity (equivalent to moratorium). In the final stage, which usually occurs in late adolescence or early adulthood, individuals achieve a complete sense of ethnic identity by accepting and internalizing their ethnicity. Empirical support for the three stages of ethnic identity development has been found for Asian Americans, African Americans, and Latinos (Phinney, 1989, 1990). For example, Mexican American children tend to have a clear sense of themselves as part of a distinct group by age 7 (Bernal et al., 1990). As they enter adolescence, the process of defining themselves as part of an ethnic group through 
increased exploration and understanding of their ethnicity is evident (Phinney, 1989, 1992). This research provides a description of the stages of ethnic identity formation; however, empirical research on the process of ethnic identity formation specific to Latinos is sparse, and many unanswered questions remain.

One issue that has not been fully explored is when the process of ethnic identity development is typically completed. Erickson (1968) theorized that identity formation occurred primarily during adolescence, but the lengthening of this period in Western societies to allow extended schooling has led to an extension of identity formation into young adulthood (Meeus, Iedema, Helsen, \& Vollebergh, 1999; Waterman, 1999). Empirical studies of ego identity development suggest that the majority of White, middleclass young adults have not reached identity achievement by the age of 21 (Kroger, 1999). Similarly, research on ethnic identity among Latinos indicates that ethnic identity consolidates with age as individuals develop the ability to reflect on and understand the importance of their ethnicity and have more chances to interact with people from other ethnic groups (Phinney, 1992, 1996; Rotheram-Borus, Lightfoot, Moraes, Dopkins, \& LaCour, 1998). The process appears to parallel that of ego identity formation, with the majority of young adolescents in the process of exploring their identity and the majority of college-age students reporting an achieved ethnic identity (Phinney, 1989, 1992). There is limited empirical evidence linking age and ethnic identity achievement, however, and individuals may reexamine aspects of their identity throughout their life and not proceed through the stages in an invariant order (Phinney, 1996). Because most research on ethnic identity has involved individuals under the age of 21 , the full course of ethnic identity development is not represented in the current literature. Thus, our first goal was to examine ethnic identity in a sample of Latino young adults ranging in age up to 30 years.

A second issue that has not been fully addressed in previous research with Latinos involves the identification of demographic factors linked to differences in ethnic identity. Research on earlier European immigration suggests that individuals from the same geographic region only develop a sense of a larger ethnic community in response to postimmigration experiences. For example, Italian immigrants of the late 19th century tended to identify themselves as Sicilians, Calabrians, or Neapolitans rather than as Italians; an Italian American ethnic identity emerged as a result of how immigrants were treated in the United States (Yancey, Ericksen, \& Juliani, 1976). This suggests that a sense of ethnic identity may depend, in part, on demographic factors such as time and experience in the United States. Research on how Latino ethnic identity varies according to demographic factors is quite limited. A review by Hurtado (1995) revealed that although ethnic labels vary by generation and language, ethnic identity remains strong. Other studies have found no relation between ethnic identity development and social class in Hispanics, as well as in African American and Asian American high school and college students (Phinney, 1989, 1992). Furthermore, research conducted with multiple ethnic groups reveals no consistent pattern of relations between ethnic identity and generational status (Phinney, 1990). Taken together, these studies suggest that demographic factors may not be significant predictors of ethnic identity. However, researchers have used a variety of methods and have not simultaneously examined a full range of demographic factors, making it impossible to draw firm conclusions. Despite sharing a common heritage of Spanish colonization and geographic proximity, there are significant differences between Latino subgroups, including diversity in timing of migration, national origin, and postmigration experiences (Rumbaut, 1996). Thus, in the current study, we examined interrelationships between ethnic identity and factors that differentiate among Latino subgroups, including SES, time in the United States, and acculturation.

A third issue is what types of experiences influence ethnic identity development. Theorists suggest that family and peer contexts may play significant roles. For example, Phinney (1992) proposes that individuals enter adolescence with a view of their ethnic heritage that has been shaped by family influences and involvement in the ethnic community. For Latinos, much of this influence may come in indirect forms such as the implicit teaching of the concepts of familia (deep connection and loyalty to extended family) and respeto (respect of elders). Direct teaching within the family may also be an important influence on ethnic identity development. Knight and colleagues (Knight, Bernal, Garza, Cota, \& Ocampo, 1993; Knight, Cota, \& Bernal, 1993) have examined a socialization model in which parental factors (e.g., ethnic knowledge, generation of immigration) influence the parents' teaching of the Mexican culture to their children, which, in turn, influences children's ethnic identity. Similarly, Phinney, Romero, Nava, and Huang (2001) report a significant relation between parental cultural-maintenance behaviors (e.g., discussing ethnic history, encouraging children to learn cultural traditions) and ethnic language proficiency, which tends to be highly related to ethnic identity status. These studies suggest that family experiences may influence the process of ethnic identity development in young children, although the impact on older adolescents remains unexplored.

Although the family context represents a significant source of socialization surrounding identity formation, the construct of ethnic identity assumes a contrast group (Phinney, 1990). For ethnic adolescents, the peer group may be an important source of contrasting socialization experiences. Given the significant amount of socialization adolescents receive from peers 
(Rubin, Bukowski, \& Parker, 1998), it is likely that the peer group also affects ethnic identity development by either reinforcing the values adolescents receive at home or by providing a contrast if they are from traditional homes. Indeed, Mexican, Armenian, and Vietnamese adolescents who interacted with peers from the same ethnic group tended to have a more consolidated ethnic identity status (Phinney et al., 2001). Similarly, recent Mexican immigrants and those who identified as Mexican American tended to be involved in school activities related to their ethnicity and to speak Spanish with their families and friends; in contrast, students of Mexican descent who identified as Chicano were less likely to be involved in school programs (Matute-Bianchi, 1986). Several researchers have also reported that adolescents' feelings regarding their ethnicities vary depending on the social context. In one study, Cuban American adults had higher Cuban identity scores when they were entrenched within Cuban communities (Garcia \& Lega, 1979). Similarly, Greek Australian and Italian Australian adolescents reported feeling more Greek or Italian while around others of their ethnic group or while participating in traditional activities; in contrast, they felt more Australian when in school and participating in mainstream recreational activities (Rosenthal \& Hrynevich, 1985). Taken together, this research led us to speculate that family and peer factors would influence ethnic identity exploration and development.

In sum, the goal of the current analysis was to build on existing knowledge in three ways. First, we examined ethnic identity during late adolescence and early adulthood, complementing prior research that has focused mainly on younger age groups. Second, we investigated the possible influence of factors that differentiate between Latino subgroups, yielding a more nuanced understanding of Latino ethnic identity development. Third, we extended existing research on the developmental significance of families and peer groups by examining their influences on ethnic identity in young adulthood.

\section{METHOD}

\section{Participants and Procedures}

The sample was drawn from a larger study targeting 19- to 45-year-olds who self-identify as Latino or Hispanic. With the cooperation of four midwestern postsecondary institutions (two state universities, one community college, and one private university), survey packets and subsequent reminder postcards were sent to all currently enrolled Latino or Hispanic undergraduate and graduate students. Depending on the institution, respondents either received $\$ 10$ and were entered into a drawing for an additional bonus payment of $\$ 50$ or were paid $\$ 15$ for completing the survey. To protect students' privacy, survey packets were mailed directly by each institution's registration department; the investigator did not have access to any identifying or demographic information. At three institutions, it was not possible to restrict the mailing to students in the target age range, so the mailing was sent to all currently enrolled Hispanic students. Students were instructed not to return the survey if they were younger than 19 or older than 45 . Thus, the exact number of students who were eligible to participate is unknown. Eight hundred and seventy one surveys were mailed; 26 were undeliverable or recipients informed the investigator that they were ineligible. Of the remaining 845 surveys, 242 (28.6\%) were returned. To limit sample heterogeneity, the current analysis was restricted to the 200 respondents between the ages of 19 and 30 ( $83 \%$ of the original sample).

Sample description. The sample consisted of 117 female and 83 male young adults (mean age $=22.5$ ). Respondents were highly educated: $6 \%$ had completed high school or a general equivalency diploma; $80 \%$ ( $\mathrm{n}=$ 160) were either pursuing or had obtained a college degree; and 14\% ( $\mathrm{n}=$ 28) were either pursuing or had a graduate or professional degree. Most respondents were not married $(\mathrm{n}=163 ; 81.5 \%) ; 15.5 \%(\mathrm{n}=31)$ were married; $2.5 \%(n=5)$ were separated or divorced; and 1 respondent lived with a life partner. Respondents lived in college housing $(17 \% ; n=34)$, in apartments alone or with roommates $(33 \% ; n=66)$, with parents or other relatives $(26 \% ; n=52)$, or with a spouse $(22 \% ; n=44)$. In terms of parental national origin, fathers were from 19 different countries and mothers from 22 different countries (including the United States). The majority of respondents had two U.S.-born parents $(\mathrm{n}=112 ; 56.3 \%)$, whereas $18.6 \%(\mathrm{n}=37)$ had at least one parent from Mexico; 21.6\% $(n=43)$ had at least one parent from a South American country; and 3.5\% $(n=7)$ had at least one parent from another country.

\section{Measures}

Surveys included demographic information and ethnicity-related measures. Measures are described below; descriptive statistics are listed at the bottom of Table 1.

Demographics. Individuals reported on their gender, age, and years of education completed by each parent. A combined score for parental education was obtained by averaging mother's and father's years of education $(\mathrm{r}=.65, \mathrm{p}<.001)$. 


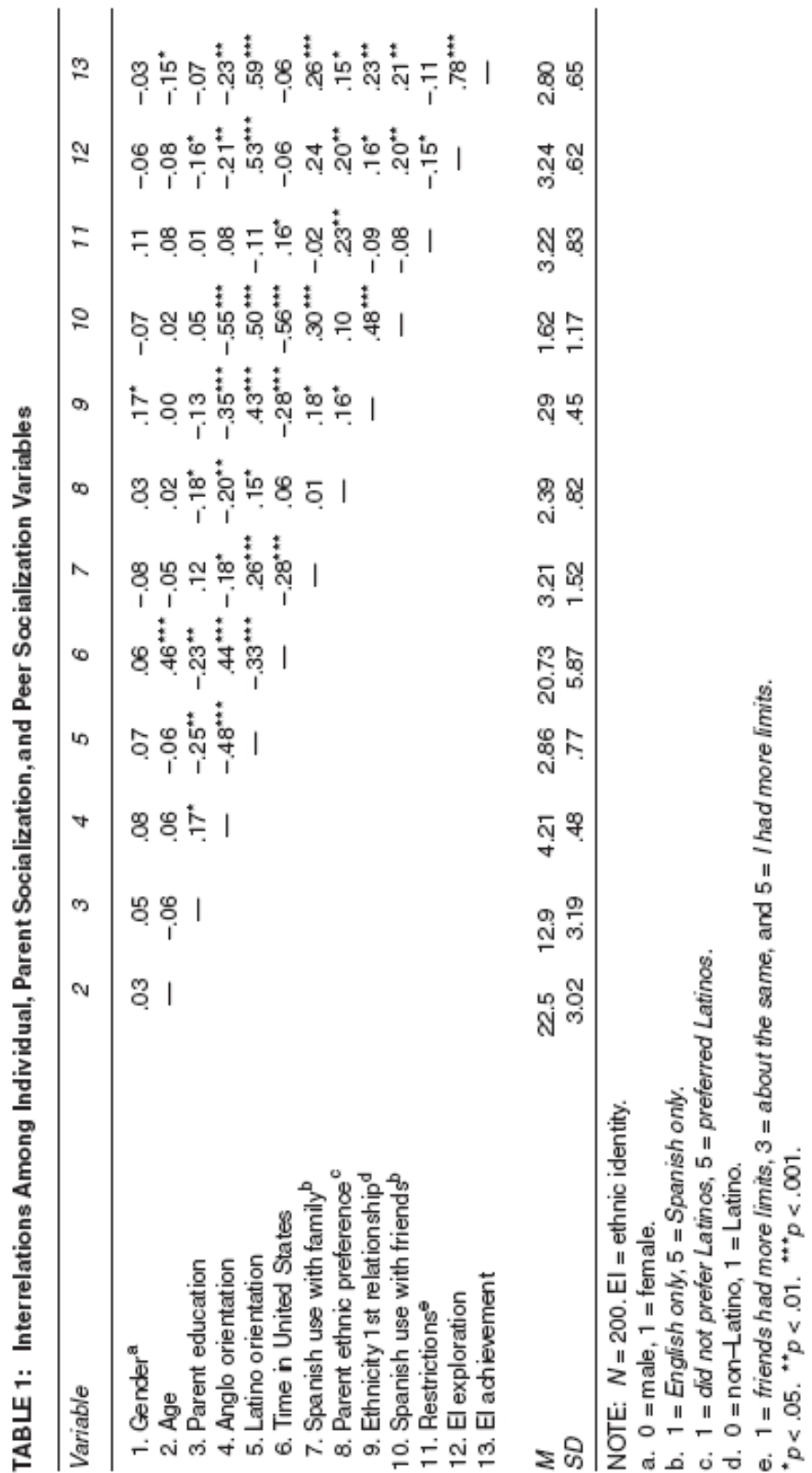

Acculturation. Subjective aspects of acculturation were assessed using the Acculturation Rating Scale for Mexican Americans-II (Cuellar, Arnold, $\&$ Maldonado, 1995). The instructions were altered to read the following:

This scale was originally designed for Mexican-Americans. If you are not of Mexican heritage, please substitute whatever country your family comes from as you fill out the scale. For example, if your family is from Chile, wherever the scale says "Mexico" or "Mexicans" you should respond as if it said "Chile" or "Chileans".

No other changes to the instrument were made. Two scores were derived from this scale. Anglo orientation consists of 13 items assessing the degree to which the respondent has been exposed to and adheres to Anglo American culture. Latino orientation (equivalent to the original Mexican orientation scale) consists of 17 items assessing the degree to which the respondent has been exposed to and adheres to traditional cultural practices (e.g., Spanish language use and preference, parental identification as Mexican). Items were rated on a 5 -point scale $(1=$ not at all to $5=$ extremely often or almost always) and averaged to form an overall score. Reliabilities in the current sample were comparable to those reported by Cuellar et al. (1995): Anglo orientation alpha $=.97$; Latino orientation alpha $=.88$. Length of time in the United States was computed in years.

Family socialization. Two aspects of ethnic socialization within the family of origin were assessed. Spanish use with family while growing up was computed as a mean of four items (alpha $=.95$ ), assessing language use with father, mother, brothers or sisters, and relatives (scored on a 5-point scale; $1=$ English only, $3=$ both the same, and $5=$ Spanish only). Parental preference about the ethnicity of dating partners during the respondents' adolescence was assessed with three items (scored on a 5-point scale; $1=$ disagree strongly, $3=$ in the middle, and $5=$ agree strongly) for mothers and fathers separately (e.g., "This parent told me I could only date people of the same ethnic group as our family"). Responses to the six items were averaged and an overall score computed for each respondent (alpha $=.76$ ), with a higher score indicating that parents preferred their child to date within their ethnic group.

Peer socialization. Three measures of peer-group influence were assessed. Ethnicity of first serious or steady relationship was coded as 0 $=$ non-Latino or $1=$ Hispanic or Latino. Spanish use with friends while growing up was assessed with a single item (scored on a 5-point scale from $1=$ English only to $5=$ Spanish only). Finally, respondents rated 
the extent of behavioral restrictions relative to same-sex friends in 10 areas (e.g., "How late you could stay out on weeknights"; "When you could start dating"; "Having friends of the opposite sex"). Each item was scored on a 5-point scale $(1=$ friend had more limits, $3=$ about the same, and 5= I had more limits) and an overall limits scale computed (alpha $=.90)$.

Ethnic identity. The Multigroup Ethnic Identity Measure (MEIM) (Phinney, 1992) was administered and scored according to recent studies of adolescents from diverse backgrounds (Roberts et al., 1999; Spencer, Icard, Harachi, Catalano, \& Oxford, 2000). The revised MEIM consists of 12 items (one item loads on both subscales) rated on a 4-point scale (1 = strongly disagree to $4=$ strongly agree $)$. Exploration $(6$ items, alpha $=.75)$ assesses the extent to which individuals have explored or are currently exploring the meaning of their ethnic identity (e.g., "I have spent time trying to find out more about my own ethnic group, such as its history, traditions, and customs"). The achievement (affirmation and belonging) subscale (7 items, alpha $=.88$ ) taps the extent to which individuals have formed a clear sense of their ethnic identity and what it means in their life (e.g., "I have a strong sense of belonging to my own ethnic group").

\section{RESULTS}

\section{Bivariate Relations Between Ethnic Identity and Individual and}

\section{Socialization Factors}

Correlations were computed to examine bivariate relations between ethnic identity measures and demographic, acculturation, family socialization, and peer socialization variables (see Table 1). Both components of ethnic identity (exploration and achievement) were significantly associated with subjective measures of acculturation (negatively with Anglo orientation, positively with Latino orientation) and with parental preference for Latino dating partners, speaking Spanish with family and friends, and having a first relationship with a Latino or Latina. Few significant relations between ethnic identity and demographic variables were found; exploration was negatively associated with parent education and achievement was negatively associated with age. Correlations between predictor variables are also shown in Table 1.
TABLE 2: Regression of Individual and Social Factors on Ethnic Identity



NOTE: $N=183$. Values are standardized regression $\infty$ efficients (betas). Males coded as 0 , females coded as 1 .

a. Step $1 R^{2}=.61^{* * *}$; Step $2 R^{2}=.61^{* * *}$; Step $3 R^{2}=.62^{* * *}$; Step $4 R^{2}=.63^{* *}$ b. Step $1 R^{2}=.61^{* * *}$; Step $2 R^{2}=.69^{* * *}$; Step $3 R^{2}=.70^{* * *}$; Step $4 R^{2}=.70^{* *}$

${ }^{*} p<.05 .{ }^{*} p<.01 .{ }^{* * *} p<.001$.

\section{Predictors of Ethnic Identity}

To assess the relations of demographic, acculturation, and socialization factors with components of ethnic identity, hierarchical multiple regressions were computed separately for exploration and achievement. Variables were entered in four steps: demographics (gender, age, and parent education), acculturation variables (Anglo orientation, Latino orientation, and time spent in the United States), family socialization variables (Spanish use with family and parents' preferences for Latino partners), and peer socialization factors (experiencing a first romantic relationship with a Latino, speaking Spanish with friends, and having more restrictions than friends) (see Table 2). To control for the significant bivariate relation between the two dependent variables, exploration was entered in the first step of the regression 
predicting achievement, and achievement was entered in the first step of the regression predicting exploration.

At the first step, demographic and control variables accounted for a significant amount of variance in ethnic identity (exploration, F[4, 171] $=65.92, \mathrm{p}<.001$; achievement, $\mathrm{F}[4,171]=65.98, \mathrm{p}<.001)$. Acculturation variables entered at the second step explained a significant additional amount of variance for achievement but not exploration (exploration, $\mathrm{F}_{\text {change }}[3,168]=.90, \mathrm{~ns}$; achievement, $\left.\mathrm{F}_{\text {change }}[3,168]=15.86, \mathrm{p}<.001\right)$ At Step 3, family socialization variables did not add a significant amount of explained variance (exploration, $\mathrm{F}_{\text {change }}[2,166]=1.88$, ns; achievement, $\mathrm{F}_{\text {change }}[2,166]=.28$, ns). Similarly, the addition of peer socialization variables on the fourth step did not add a significant amount of explained variance to either component of ethnic identity (exploration, $\mathrm{F}_{\text {change }}[3,163]=$ 1.72 , ns; achievement, $\mathrm{F}_{\text {change }}[3,163]=.92$, ns). In the final model for exploration (multiple $\mathrm{R} 2=.63, \mathrm{~F}[12,163]=23.43, \mathrm{p}<.01$ ), only parent education and parent ethnicity preference were significantly related to ethnic identity exploration: Respondents who had less educated parents and whose parents preferred that they date Latinos had higher levels of ethnic identity exploration. The final model for achievement (multiple R2 $=.70, \mathrm{~F}[12$, $163]=31.65, \mathrm{p}<.001)$ showed a different pattern: Respondents who were younger, had more educated parents, had higher levels of Latino orientation, and had spent more time in the United States tended to have higher levels of ethnic identity achievement.

\section{DISCUSSION}

By the year 2050, Hispanics will make up about one quarter of the U.S. population. Despite this fact, remarkably little is known about Latino youth and their families. The current analysis examined ethnic identity formation during late adolescence and young adulthood. Based on a review of the theoretical and empirical literature, we identified three questions to address in a sample of Latino young adults attending institutions of higher education in the Midwest. The goals of our analysis were to (a) describe ethnic identity development across late adolescence and early adulthood, (b) examine individual factors linked to ethnic identity development, and (c) explore social influences on ethnic identity. In our discussion, we address findings relating to each of these goals and suggest directions for future research.

The first goal was to examine age-related patterns in ethnic identity across late adolescence and early adulthood (for ages 19 to 30). In multivariate analyses, no age differences emerged for ethnic identity exploration, but younger respondents reported higher levels of ethnic identity achieve- ment than did older respondents. Because most research on ethnic identity has involved high school and college students under the age of 21 , it is not possible to compare these findings to those from other studies. However, the findings do support the notion that the process of ethnic identity formation is largely complete by late adolescence, as has been reported in prior research with college students (Phinney, 1989, 1992). The lack of age differences in levels of ethnic identity exploration in the current sample of Latino young adults suggests that exploration has ended by the college years. Moreover, identity theorists posit that adolescence and early adulthood are times when identity issues are particularly salient; thus, the finding that younger individuals have higher levels of ethnic identity achievement is consistent with theoretical predictions. Because the current study was cross-sectional, it was not possible to examine individual trajectories of identity development; future longitudinal research is needed to examine individual variations in the timing and course of ethnic identity development.

A second goal of the current analysis was to identify factors linked to Latino ethnic identity. As discussed earlier, Latino subgroups differ on a number of dimensions that might be linked to ethnic identity. Therefore, we examined a set of demographic factors identified as potential sources of variations in ethnic identity exploration and achievement. In multivariate analyses, only parent education was a significant (negative) predictor of ethnic identity exploration; acculturation factors were not associated with exploration scores. In contrast, respondents whose parents had higher levels of formal education tended to report higher levels of ethnic identity achievement. Parental education may be an indicator of the kinds of opportunities individuals have had to engage in ethnic identity exploration and, thus, ultimately to form a strong sense of ethnic identity. For example, the differential associations between parent education and ethnic identity exploration and achievement may reflect socioeconomic differences in available opportunities for interacting with people from different groups, which has been linked to reflection about ethnic identity (Phinney 1992, 1996).

In addition, respondents who reported higher levels of Latino orientation and had spent more time in the United States had higher levels of ethnic identity achievement. These findings are consistent with prior research and with theoretical models of ethnic identity formation. It is not surprising that individuals who score high on Latino orientation would have a clear understanding of their ethnicity as both acculturation and ethnic identity achievement involve exposure to cultural practices that provide opportunities for reflection. The finding that time spent in the United States was positively related to ethnic identity achievement reinforces the notion that ethnic identity development requires a contrast group (Phinney, 1990). Ethnical- 
ly diverse adolescents and young adults immersed in a multicultural society are likely to think about their ethnicity in a different way than individuals in a monocultural society or those who have recently arrived in a new country. Future research is needed to examine the mechanisms by which demographic factors influence ethnic identity development; for example, it would be extremely informative to study changes across time in how Latino immigrants think about their ethnicity.

The third goal of our analysis was to examine social influences during the teen years on ethnic identity development. In bivariate analyses, respondents who dated a Latino in their first relationship and used Spanish with friends had higher levels of ethnic identity exploration and achievement. These results are consistent with prior reports that minority adolescents who are engaged in their culture through language, friends, and cultural activities also have higher levels of ethnic identity (Phinney, 1990). Moreover, respondents who reported fewer social restrictions as compared with friends tended to have higher ethnic identity exploration scores, suggesting that having freedom to participate in social activities during adolescence may provide opportunities for exploring the meaning of one's ethnicity. This is consistent with the notion that individuals confronted with a contrast group are forced to explore what their ethnicity means to them. However, although the bivariate analyses supported the hypothesis that family and peer socialization factors contribute to ethnic identity formation, the multivariate analyses did not support these associations once demographic and acculturation variables were taken into account. Only parents' ethnicity preference for their adolescents' dating partners was a significant independent predictor of exploration (although family variables did not add significantly to the overall model), such that respondents whose parents preferred that they date Latinos reported higher levels of ethnic identity exploration.

The weak predictive value of socialization variables in relation to individual variables may be because of the differential impact of family factors at different developmental stages. Phinney (1989) proposes that children enter adolescence with a view of their ethnicity that has been largely defined by their family. However, once in adolescence, they begin an independent, active exploration of the meaning of their ethnic identity. Thus, by the late teens and early 20 s, prior family influences may have an indirect effect on ethnic identity, and other factors, such as living in more diversified communities, have a more direct impact. This possibility should be explored in future longitudinal research that examines the contribution of individual, social, and community factors to the course of ethnic identity formation at different developmental stages. For example, future research could investigate how parents in ethnic minority families affect their chil- dren's friendships and activities and how differences in these social experiences are linked to ethnic identity development.

This study has several limitations that suggest directions for future research. One limitation is the retrospective nature of the questions regarding family and peer socialization, as these questions limit our ability to discern the direction of influence among study variables. Clearly, causal pathways cannot be identified without prospective research. A second limitation is that the sample is not representative of the general U.S. population of Latinos. The sample consisted of undergraduate and graduate students, and in 1996, just one fifth of Hispanics ages 18 to 24 were attending college (Wilds \& Wilson, 1998). Therefore, the findings from this study cannot be generalized to Latino young adults who do not have the opportunity to attend college. Finally, our sample was extremely heterogeneous in terms of parental national origin or descent; respondents' parents represented 22 different countries, but the sample size did not permit us to examine subgroup variations. The issue of how families from different national backgrounds socialize their children is an important avenue for future research. Despite these limitations, this study builds on prior ethnic identity research and provides novel information regarding ethnic identity development among Latinos.

\section{REFERENCES}

Arnett, J. J. (2001). Adolescence and emerging adulthood: A cultural approach. Englewood Cliffs, NJ: Prentice Hall.

Bernal, M. E., \& Knight, G. P. (1997). Ethnic identity of Latino children. In J. G. Garcia \& M. C. Zea (Eds.), Psychological interventions and research with Latino populations (pp. 15-38). Boston: Allyn \& Bacon.

Bernal, M. E., Knight, G. P., Garza, C. A., Ocampo, K. A., \& Cota, M. K. (1990). The development of ethnic identity in Mexican-American children. Hispanic Journal of Behavioral Sciences, 12, 3-24.

Cuellar, I., Arnold, B., \& Maldonado, R. (1995). Acculturation Rating Scale for Mexican Americans-II: A revision of the original ARSMA scale. Hispanic Journal of Behavioral Sciences, 17, 275-304

Erickson, E. H. (1968). Identity: Youth and crisis. New York: Norton.

Garcia, M., \& Lega, L. (1979). Development of a Cuban ethnic identity questionnaire. Hispanic Journal of Behavioral Sciences, 1, 247-261.

Hurtado, A. (1995). Variations, combinations, and evolutions: Latino families in the United States. In R. E. Zambrana (Ed.), Understanding Latino families: Scholarship, policy, and practice (pp. 40-61). Newbury Park, CA: Sage.

Knight, G. P., Bernal, M. E., Garza, C. A., \& Cota, M. K. (1993). A social cognitive model of the development of ethnic identity and ethnically based behaviors. In M. E. Bernal \& G. P. Knight (Eds.), Ethnic identity: Formation and transmission among Hispanics and other minorities (pp. 213-234). Albany: State University of New York Press. 
Knight, G. P., Bernal, M. E., Garza, C. A., Cota, M. K., \& Ocampo, K. A. (1993). Family socialization and the ethnic identity of Mexican-American children. Journal of Cross-Cultural Psychology, 24, 99-114.

Knight, G. P., Cota, M. K., \& Bernal, M. E. (1993). The socialization of cooperative, competitive, and individualistic preferences among Mexican American children: The mediating role of ethnic identity. Hispanic Journal of Behavioral Sciences, 15, 291-309.

Kroger, J. (1999). Identity development: Adolescence through adulthood. London: Sage.

Marcia, J. E. (1966). Development and validation of ego-identity status. Journal of Personality and Social Psychology, 3, 551-558.

Marcia, J. E. (1980). Identity in adolescence. In J. Adelson (Ed.), Handbook of adolescent psychology (pp. 156-187). New York: John Wiley.

Matute-Bianchi, M. (1986). Ethnic identities and pattern of school success and failure among Mexican-descent and Japanese-American students in a California high school: An ethnographic analysis. American Journal of Education, 95, 233-255.

Meeus, W., Iedema, J., Helsen, M., \& Vollebergh, W. (1999). Patterns of adolescent identity development: Review of literature and longitudinal analysis. Developmental Review, 19, 419-461.

Phinney, J. S. (1989). Stages of ethnic identity development in minority group adolescents. Journal of Early Adolescence, 9, 34-49.

Phinney, J. S. (1990). Ethnic identity in adolescents and adults: Review of research. Psychological Bulletin, 108, 499-514.

Phinney, J. S. (1992). The Multigroup Ethnic Identity Measure: A new scale for use with diverse groups. Journal of Adolescent Research, 7, 156-176.

Phinney, J. S. (1996). Understanding ethnic diversity: The role of ethnic identity. American Behavioral Scientist, 40, 143-152.

Phinney, J. S., \& Kohatsu, E. L. (1997). Ethnic and racial identity development and mental health. In J. Schulenberg, J. L. Maggs, \& K. Hurrelmann (Eds.), Health risks and developmental transitions during adolescence (pp. 429-443). New York: Cambridge University Press.

Phinney J. S., Romero, I., Nava, M., \& Huang, D. (2001). The role of language, parents and peers in ethnic identity among adolescents in immigrant families. Journal of Youth and Adolescence, 30, 135-153.

Roberts, R. E., Phinney, J. S., Masse, L. C., Chen, Y. R., Roberts, C. R., \& Romero, A. (1999). The structure of ethnic identity of young adolescents from diverse ethnocultural groups. Journal of Early Adolescence, 19, 301-322.

Rosenthal, D., \& Hrynevich, C. (1985). Ethnicity and ethnic identity: A comparative study of Greek-, Italian-, and Anglo-Australian adolescents. International Journal of Psychology, 20, 723-742.

Rotheram-Borus, M. J., Lightfoot, M., Moraes, A., Dopkins, S., \& LaCour, J. (1998). Developmental, ethnic and gender differences in ethnic identity among adolescents. Journal of Adolescent Research, 13, 487-507.

Rubin, K. H., Bukowski, W., \& Parker, J. G. (1998). Peer interactions, relationships, and groups. In W. Damon (Series Ed.) \& N. Eisenberg (Vol. Ed.), Handbook of child psychology: Social and personality development (Vol. 3, pp. 619-700). New York: John Wiley.
Rumbaut, R. G. (1996). Origins and destinies: Immigration, race, and ethnicity in contemporary America. In S. Pedraza \& R. G. Rumbaut (Eds.), Origins and destinies: Immigration, race, and ethnicity in America (pp. 21-42). Belmont, CA: Wadsworth.

Spencer, M. S., Icard, L. D., Harachi, T. W., Catalano, R. F., \& Oxford, M. (2000). Ethnic identity among monoracial and multicultural adolescents. Journal of Early Adolescence, 20, 365-387.

Tajfel, H. (1981). Human groups and social categories. UK: Cambridge University Press. Waterman, A. S. (1999). Issues of identity formation revisited: United States and the Netherlands. Developmental Review, 19, 462-479.

Waterman, A. S., Geary, P. S., \& Waterman, C. K. (1974). A longitudinal study of changes in ego identity status from the freshman to the senior year at college. Developmental Psychology, 10, 387-392.

Waterman, A. S., \& Goldman, J. A. (1976). A longitudinal study of ego identity development at a liberal arts college. Journal of Youth and Adolescence, 5, 361-369.

Wilds, D. J., \& Wilson, R. (1998). Sixteenth annual status report on minorities in higher education. Washington, DC: American Council on Education. Yancey, W. L., Ericksen, E. P., \& Juliani, R. N. (1976). Emergent ethnicity: A review and reformulation. American Sociological Review, 41, 391-403.

Lenna L. Ontai-Grzebik received her Ph.D. from the University of Nebraska, Lincoln, in August of 2002 and is currently an assistant specialist in cooperative extension in the Department of Human and Community Development at University of California, Davis. Her current research projects focus on parent socialization of children's social and emotional development and patterns of socialization within Latino families in the United States.

Marcela Raffaelli is an associate professor at the University of Nebraska, Lincoln, where she holds a joint appointment in the Department of Psychology and the Institute for Ethnic Studies. She received her Ph.D. in psychology and human development from the University of Chicago and was a postdoctoral researcher at Johns Hopkins University and Rutgers University Her current research projects focus on cultural and familial influences on adolescent and young adult development. 